Int. J. Electrochem. Sci., 12 (2017) 10152 - 10176

\title{
Failure Pressure Estimations for Pipes with Combined Corrosion Defects on the External Surface: A Comparative Study
}

G. Terán ${ }^{1 *}$, S. Capula-Colindres ${ }^{1}$, J.C. Velázquez ${ }^{1,2 *}$, M. J. Fernández-Cueto ${ }^{3}$, D. Angeles-Herrera ${ }^{4}$, Héctor Herrera-Hernández.

${ }^{1}$ Departamento de Ingeniería Química Industrial, ESIQIE, IPN, UPALM EDIF. 7, Zacatenco, Mexico City, Mexico CP 07738.

${ }^{2}$ Gerencia de Ingeniería y Costos, Pemex Transformación Industrial, Petróleos Mexicanos, Piso 6, Edificio B1, Marina Nacional 239 Col. Petróleos Mexicanos, Mexico City, Mexico, CP 11311.

${ }^{3}$ Instituto Tecnológico de Tuxtepec, Av. Dr. Victor Bravo Ahuja s/n, col. 5 de Mayo Tuxtepec, Oaxaca, Mexico, CP 68350.

${ }^{4}$ Instituto Mexicano del Petróleo, Eje central Lázaro Cárdenas 152, Col. San Bartolo Atepehuacan, Mexico City, Mexico, CP 07730.

${ }^{5}$ Universidad Autónoma del Estado de México, IIN-Lab. de Electroquímica y Corrosión de Materiales Industriales, Blvd. Universitario s/n, Predio San Javier Atizapán de Zaragoza, Estado de Mexico 54500, Mexico.

*E-mail:gerardoteranm@gmail.com,jcva8008@yahoo.com.mx

doi: $10.20964 / 2017.11 .86$

Received: 10 July 2017 / Accepted: 21 September 2017 / Published: 12 October 2017

In this research paper, the failure pressure predictions were obtained for a pipeline section by analyzing a combined corrosion defects, which joins together a general corrosion and a pitting corrosion defects. Well-known conventional mathematical methods were used in this study to predict the failure pressure of corroded steel pipelines, such as: B31G, RSTRENG-1, Shell-92, DNV, PCORR, and Fitnet FFS. The equations reported for corrosion defects with more complex characteristics developed by Choi et al., and Cronin et al. were also used. Furthermore, Finite Element (FEM) is one of the most employed nonlinear methods because of its good response of pipeline failure prediction under the corrosion mechanism. So, FEM methodology results the least conservative in comparison with the others mathematical models, according to the literature, for this reason it was used to compare the standard deviation $\sigma$ of the methods. Failure pressure predictions determined that the most conservative methods were: Shell-92, Fitnet FFS, Choi's method, B31G, RSTRENG-1, Cronin's method, PCORR and DNV, in that order.

Keywords: Corrosion Defect, Pipeline Steels, Failure Pressure and Finite Element Method. 


\section{FULL TEXT}

(C) 2017 The Authors. Published by ESG (www.electrochemsci.org). This article is an open access article distributed under the terms and conditions of the Creative Commons Attribution license (http://creativecommons.org/licenses/by/4.0/). 